\title{
ANALYSIS OF WEALTH INEQUALITY WITH A RANDOM MONEY TRANSFER MODEL
}

\author{
Siyan Chen ${ }^{1}$, Yougui Wang ${ }^{2}$, Chengyu Yang ${ }^{3}$, Saul Desiderio $^{1}$ \\ ${ }^{1}$ Business School, Shantou University \\ 243 Daxue Road, Shantou, Guangdong, P.R. China, 515063 \\ ${ }^{2}$ School of Systems Science, Beijing Normal University \\ 19, XinJieKouWai St., HaiDian District, Beijing, P.R. China, 100875 \\ ${ }^{3}$ Business School, Beijing Normal University \\ 19, XinJieKouWai St., HaiDian District, Beijing, P.R. China, 100875
}

\begin{abstract}
Increasing gap in wealth distribution is among the key issues that have been discussed worldwide in recent years. In this paper, we use the money transfer model to explain the formation of wealth distribution, by imposing two types of debt constraints, and the analytic function of wealth distribution is derived by adopting Boltzmann statistics. With a limit of individual debt, it is shown that the stationary distribution of wealth follows the exponential law, which is verified by many empirical studies. While the limit is imposed on the total amount of bank loan, the stationary distribution becomes an asymmetric Laplace one. Furthermore, an excellent agreement is found between these analytical probability density functions and numerical results by simulation at the steady state.
\end{abstract}

Key words: wealth distribution; money transfer model; debt constraints

\section{Introduction}

Increasing inequality in wealth distribution is among the key issues that have been discussed for the past decades. According to a recent study by Credit Suisse (Global Wealth Report 2016, 2017), the richest $0.7 \%$ of households hold $45.6 \%$ of total wealth in the world in 2016 , while $73.2 \%$ of households at the bottom of wealth pyramid only own $2.4 \%$ of the world wealth. The increasing gap in wealth distribution may cause even more inequality in income through asset return. Studies also show that wealth distribution of the very rich is quite different from that of the rest of the population. The study of the specific distribution law of the rich and the formation of the distribution becomes one of the important topics in inequality research.

In the recent decade, the application of statistical physics methods and techniques to economic and financial problems has gotten fruitful results (Bak et.al., 1999, Chatterjee et.al., 2005, Chakrabarti et.al., 2006, Chatterjee et.al., 2007, Basu et.al., 2010, Abergel et.al., 2011). In particular, money transfer model (or wealth exchange model) has been developed to investigate the statistical distribution of wealth via agent interactions (Chatterjee et.al., 2005, Ispolatov et.al., 1998, Drăgulescu et.al., 2000, Chakraborti et.al., 2000, Ding et.al., 2003, Fischer et.al., 2003). These studies were motivated by the common interest in the origin of power law, which was found in wealth distribution by Vilfredo 
Pareto over 100 years ago (Pareto, 1896) and was recently studied both empirically and theoretically (Benhabib et.al., 2011, Benhabib et.al., 2017, Castaneda et.al., 2003, Drăgulescu et.al., 2001). Methods of statistical mechanics are therefore adopted to mimic the formation of wealth distribution (Chatterjee et.al., 2005, Ding et.al., 2003, Chatterjee et.al., 2004, Braun, 2001, Fischer et.al., 2003, Yakovenko et.al., 2009), and empirical data of wealth among different countries and during different periods are also investigated (Drăgulescu et.al., 2001, Levy et.al., 1996, 1997, Levy, 2003, Levy et.al., 2003, Klass et.al., 2007, Sinha, 2006, Coelhe et.al., 2005, Abul-Magd, 2002, Hegyi et.al., 2007). These efforts of theoretical models have numerically shown some distribution features found in the empirical studies, like exponential behavior of the bulk, and power law in the upper tail, but studies on the formation mechanism of distribution is still very limited.

In this paper, we adopt the simple version of pairwise money transfer model [8] and add debt (Ding et.al., 2003, Braun, 2001, Fischer et.al., 2003) with different constraints to analyze the effects on formation of wealth distribution. Money, as assumed the form of wealth in the model, is represented by digits on computerized bank accounts. Increasing debt is to inject money into the economy, thus changing the total amount of wealth in the system. From the model point of view, permission of debt is to change the boundary constraints of the system, thus changing the total wealth of the agents. Hence, debt is closely associated with money flow in the economy, and any change of debt can rapidly lead to an effect on the distribution of wealth. Later researches attempt at deducing an analytic formula of wealth distribution (Drăgulescu et.al., 2000, Fischer et.al., 2003), which shed lights on the boundary conditions under random money transfer and found a variety of distributions. Despite the fact that these works are more of physics-oriented approach and lack of exact match in real economies, it suggests that some simply methods of statistical physics can be applied to an analytical treatment of complex behaviors in the economy, especially in the field of income and wealth distribution.

In this paper, an economy of random money transfer is investigated by considering the existence of bank, debt and credit. Our goal is to explore the underlying mechanism of the shape and formation of the equilibrium distribution of wealth. In the next section, we consider our model by introducing debt and virtual bank into the money transfer models, and define the quantity of money. Then, we deduce the analytical solution of the stationary distribution of monetary wealth, respectively under each agent's debt limit and the total amount of bank credit, as well as the results from numerical simulations. Finally we make our conclusion in the last section.

\section{Money transfer model with debt}

It is an economic system composed of $N$ economic agents and one bank. Essentially, a virtual bank should be introduced, because bank loans ensure an efficient money creation and money redistribution. If there is no bank lending in the economy, the disposable money $M$ equals to the initial money $M_{0}$, that is, the total money. But if bank credit is allowed, the disposable money $\left(M=M_{0}+D\right)$ in the economy amounts to the sum of initial money $M_{0}$ and bank loan volume $D$, even though the total balance of money for each agent is still conservative. In this case, some agents have more disposable money at the sacrifice of others' going into debt. In other words, it is by introducing a bank that money distributes asymmetrically. 
Now that the bank is brought in, agents could deposit and borrow in the bank. Initially, each of the $N$ agents possesses certain currency units $m_{0}$ only in deposit form. At each time each agent interacts with one partner randomly, which generates $N$ trading pairs. For each trading pair, one is picked as "winner" randomly and the other as "loser". Meanwhile one unit of money is transferred. Concretely, if a loser has deposits in the bank, he pays one unit to the winner. Otherwise, a loser may borrow from the bank, and his account of liability increases by one unit. For an agent indebted, when he receives money as a "winner", he uses this money to fill and level up his liability account. In particular, the trade would be cancelled when the bank has to refuse the losers' demand for borrowing due to the boundary constraint of debt. For simplicity, we assume that the bank charges no interest for the lent money.

Supposedly, not only can agents deposit money, but also they can borrow money from the bank. So we set up a virtual deposit and liability account for each agent. In order to describe simply, we define the amount of money of any agent $i$ as

$$
m_{i}=s_{i}-l_{i}
$$

where $m_{i}$, the amount of money of agent $i$, is the total balance between his deposit account and liability account. At the beginning, each agent has the same amount of money. Then, as trading is proceeding among agents, the quantity of any individual's money varies by one unit each time. According to the definition in Equation (1), we divide the agents in an economic system into three groups: $\left\{n_{+}\right\}$(agents with positive amount of money), $\left\{n_{-}\right\}$ (agents in debt/with negative money) and $\left\{n_{0}\right\}$ (agents whose amount of money is zero). Meanwhile, the number of agents holding the same amount of money varies till it is eventually stabilized by the boundary constraint of debt. In other words, even though changes in the amount of money for each agent take place all the time, the macroscopic distribution of wealth arrives at a steady state due to the boundary condition of debt. Based on this model, we will investigate the equilibrium statistical distribution of wealth under different boundary conditions of debt in the following sections.

\section{Model with maximum individual debt}

In the money transfer model, the equilibrium statistical distribution of wealth shapes when the system is driven to get steady by the boundary conditions. Referring to the debt constraints, two kinds of constraints have been considered: one is a limit of maximal individual debt; the other is a limit of maximal bank credit. As mentioned above, simulation results demonstrated that their final distributions of money have remarkable different characters under such two boundary conditions. To expect more insights from the equilibrium statistical distributions, in this section and the next one we shall take an analytic treatment of wealth distribution under these two different boundary conditions of debt respectively.

In the model, debt is considered as negative wealth. When an agent " $i$ " borrows money from a bank, the asset of the agent, " $a_{i}$ " (positive wealth), increases, but the agent also acquires a same amount of liability, " $l_{i}$ " (negative wealth). So the total money balance of the agent remains the same after borrowing, but the total amount of money supply in the system increases. Obviously, an economic system cannot be stable if unlimited debt is 
permitted. So in order to prevent Ponzi's game and to ensure the stability of the system, some boundary constraints of debt are needed (this paragraph was moved here from the introduction section). Now, we postulate that an agent's debt limit is $m_{d}\left(m_{d}>0\right)$. According to the trading rules in our model, four cases of transfers contribute to the evolution of the probability distribution of wealth $P(m, t)$ for any agent having money $m$ at time $t$ :

(a) An agent with money $m+1$ gives $\Delta m=1$ to one of any other agents. This process contributes $P(m, t)$ an increase $p(m+1) \sum_{n=-m_{d}}^{\infty} p(n, t)$.

(b) An agent with money $m-1$ obtains amount $\Delta m=1$ from another agent with money $m \geq-m_{d}+1$. The process increases $P(m, t)$ by $p(m-1) \sum_{n=-m_{d}+1}^{\infty} p(n, t)$.

(c) An agent with money $m\left(m \geq-m_{d}+1\right)$ gives $\Delta m=1$ to another agent, no matter how much the other agent originally has. This leads to a decrease by $p(m, t) \sum_{n=-m_{d}}^{\infty} p(n, t)\left[1-\delta_{m\left(-m_{d}\right)}\right]$.

(d) An agent with money $m$ receives $\Delta m=1$ from another agent with money $m\left(m \geq-m_{d}+1\right) . \Delta P(m, t)$ decreases by $p(m, t) \sum_{n=-m_{d}+1}^{\infty} p(n, t)$.

These yield the following master equation, that is,

$$
\begin{gathered}
\frac{d p(m, t)}{d t}=p(m+1, t) \sum_{n=-m_{d}}^{\infty} p(n, t)+p(m-1, t) \sum_{n=-m_{d}+1}^{\infty} p(n, t)- \\
-p(m, t) \sum_{n=-m_{d}}^{\infty} p(n, t)\left[1-\delta_{m\left(-m_{d}\right)}\right]-p(m, t) \sum_{n=-m_{d}+1}^{\infty} p(n, t) .
\end{gathered}
$$

As shown in Equation (2), the first two items present the two processes which contribute an increase to the probability. Likewise, in the other two items, the negative sign presents as a decrease of the probability.

Ordering

$$
G(x, t)=\sum_{m=-m_{d}}^{\infty} x^{m} p(m, t)
$$

we get

$$
\begin{aligned}
\frac{d G(x, t)}{d t} & =\left(\frac{1}{x}-1\right)\left[G(x, t)-x^{-m_{d}} p\left(-m_{d}, t\right)\right]+ \\
& +(1-x) G(x, t)\left[p\left(-m_{d}, t\right)-1\right] .
\end{aligned}
$$

When the economic system reaches a steady state, the stationary solution $\left(\frac{d G(x, t)}{d t}=0\right)$ of Eq. (4) is 


$$
G(x)=\frac{x^{-m_{d}} p\left(-m_{d}\right)}{1-x\left[1-p\left(-m_{d}\right)\right]} .
$$

Substituting Eq. (5) into Eq. (3), we obtain

$$
p(m)=p\left(-m_{d}\right)\left[1-p\left(-m_{d}\right)\right]^{m+m_{d}} .
$$

As $m_{d}$ is given, when the economic system reaches a stationary state, the probability of $p\left(-m_{d}\right)$ is constant, that is

$$
p\left(-m_{d}\right)=\frac{1}{T}=\text { const. }
$$

Substituting Eq. (7) into Eq. (6), we have

$$
p(m) \approx \frac{1}{T} \exp \left(-\frac{m+m_{d}}{T}\right) .
$$

It is found that the equilibrium statistical distribution of wealth follows the exponential law. According to the definition of money, it exists

$$
\int_{0}^{\infty} N m p(m) d m=M .
$$

Calculating the integral equation above, we find that

$$
T e^{-\frac{m_{d}}{T}}=\frac{M}{N} .
$$

Approximately, through Taylor expansion, Equation (10) can be transformed as follows

$$
T \approx \frac{M}{N}+m_{d}
$$

Numerically, Equation (11) approximately equals to the effective temperature defined by Drăgulescu (2000). But they are essentially different. In terms of the preconditions, we take into account money creation due to bank credit, while the work by Yakovenko keeps the bank out of the system, and holds the conservation law of money in the model with debt. Even though this does not change the character of exponential decay of wealth distribution, it shows a more realistic process, including money creation.

Imposing the maximal individual debt $m_{d}$, we carry out the simulations for $N=25000$ and $m_{0}=0$. Since the system is driven to a steady state by imposing the maximal individual debt, we collect the data of $m_{i}(i=1,2, \ldots, N)$ defined by Eq. (1) at a stationary state, and the equilibrium statistical distributions of money under different imposed values of maximal individual debt $m_{d}$ are plotted in Fig. 1, where the solid line is the analytical 
function of distribution as Eq. (8). It shows an excellent agreement between the theoretical and simulation results.
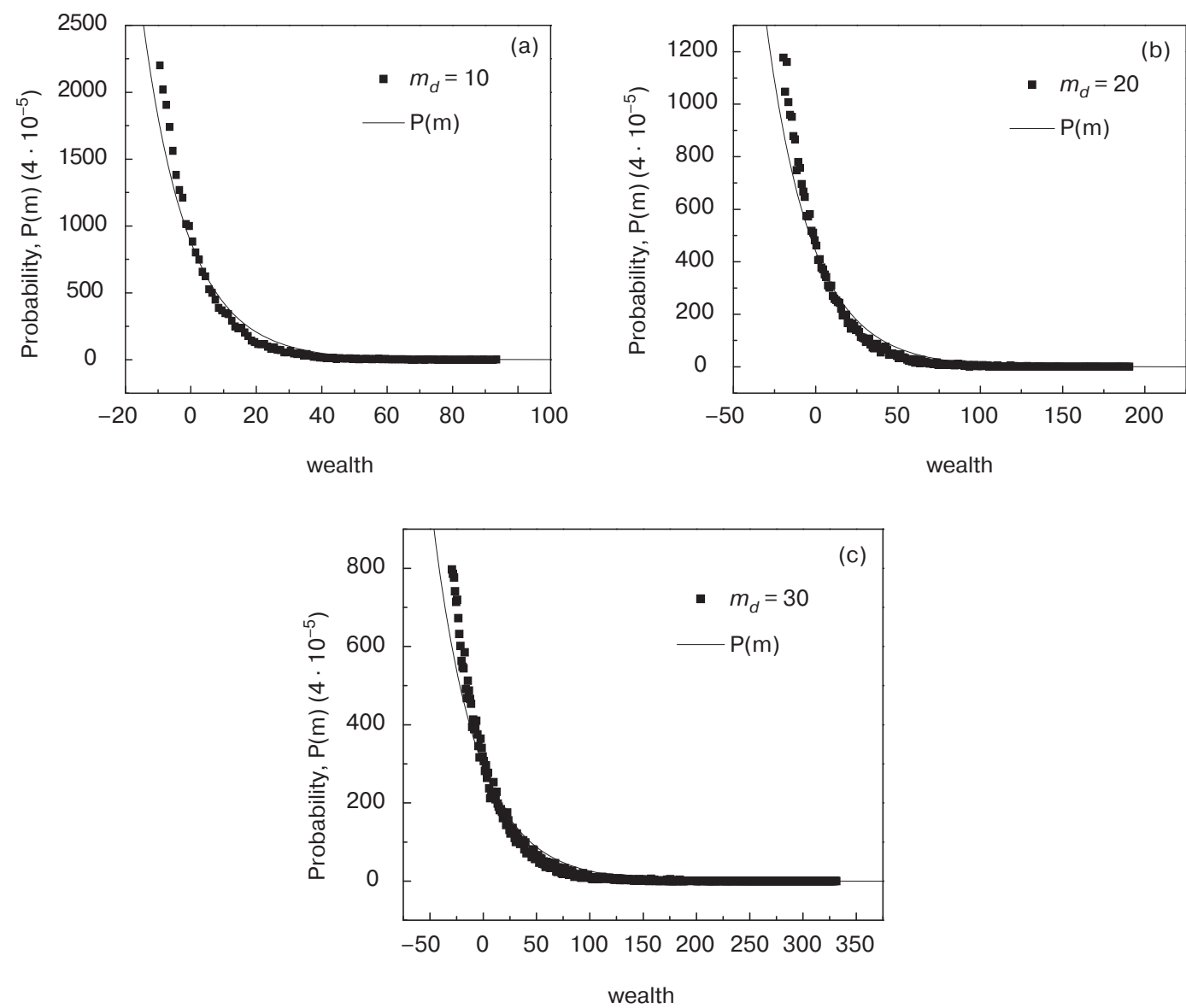

Fig. 1. The probability distribution of wealth at steady state under different value of maximal individual debt $m_{d}$. The scatter points are simulation data, which fit well with the exponential distribution function as Eq. (8) (Solid line) in all the cases.

\section{Model with maximum bank credit}

As the case stands, it is not realistic to impose a boundary condition as maximal individual debt $m_{d}$. On the one hand, the bank has a limited capability of credit. If the bank has no excess reserve, any agent could not borrow money from the bank. On the other hand, agents are different from each other. So their demands of borrowing and capacities of paying back the money are different. Thus, instead of setting a maximal debt of each agent, we consider a target quantity of bank loan $D$ on the sum of amount of liabilities for all agents, that is, $\sum_{i=1}^{N} l_{i} \leq D$. D is represented the maximal amount of bank loan. In other words, the trade would be cancelled when the bank has to refuse the losers' demand for borrowing due to its limited capacity of credit. 
According to the modified trading rules above, when $N$ agents are distributed over money, this will form a certain distribution, denoted as $\left\{n_{i}\right\}$, where $n_{0}$ agents have zero amount of money, and $n_{m_{+}}$agents hold the amount of money $m_{+}\left(m_{+}>0\right)$, and $n_{m_{-}}$agents have $m_{-}$amount of money $\left(m_{-}<0\right)$. Thus distributing $n_{i}$ agents to $m_{i}$ property classes is a question of combinatorial statistics. The number of microscopic states $W$ corresponding to this distribution $\left\{n_{i}\right\}$ can be done as

$$
W=\frac{N}{n_{0} ! \Pi_{m_{+}} n_{m_{+}} ! \Pi_{m_{-}} n_{m_{-}} !}
$$

subjected to

$$
\begin{gathered}
\delta N=\delta\left(n_{0}+\sum_{m_{+}} n_{m_{+}}+\sum_{m_{-}} n_{m_{-}}\right)=\delta n_{0}+\sum_{m_{+}} \delta n_{m_{+}}+\sum_{m_{-}} \delta n_{m_{-}}=0 \\
\delta D=\delta\left(\sum_{m_{-}} m_{-} \cdot n_{m_{-}}\right)=\sum_{m_{-}} m_{-} \cdot \delta n_{m_{-}}=0 \\
\delta M_{+}=\delta\left(\sum_{m_{+}} m_{+} \cdot n_{m_{+}}\right)=\sum_{m_{+}} m_{+} \cdot \delta n_{m_{+}}=0
\end{gathered}
$$

and

$$
\delta M_{0}=\delta\left(m_{0} \cdot N\right)=0
$$

where Equation (14) to Equation (17) are the subjected conditions at the steady state. Equation (14) shows that the number of agents is fixed on $N$. Due to the boundary constraint of debt, the amount of bank loan would eventually get to its maximum, which is the sum of agents' liability accounts (Equation (15)). Given the initial money (Equation (17)), the sum of agents' deposit accounts also reach its upper value (Equation (16)), since the total money stays at its upper limit when the system is at the steady state.

According to the Boltzmann statistics, there must be a most probable distribution which corresponds to the largest number of microscopic states. So the stationary distribution can be obtained by maximizing $\ln W$ subjected to the constraints listed from Equation (14) to Equation (17). Applying the Lagrange principle, we draw the most probable distribution followed by

$$
\delta \ln W-\alpha \cdot \delta N-\beta \cdot \delta D-\gamma \cdot \delta M_{+}-\lambda \cdot \delta M_{0}=0 .
$$

Substituting Equations (13) (17) into Equation (18) and then making a simple transformation, we get the formula of $n_{0}, n_{m_{+}}$and $n_{m_{-}}$, that is

$$
n_{0}=e^{-\alpha-\lambda m_{0}}
$$




$$
\begin{aligned}
& n_{m_{+}}=e^{-\alpha-\lambda m_{0}-\gamma m_{+}}=n_{0} e^{-\gamma m_{+}} ; \\
& n_{m_{-}}=e^{-\alpha-\lambda m_{0}-\beta m_{-}}=n_{0} e^{-\beta m_{-}}
\end{aligned}
$$

where the Lagrange multipliers are

$$
\begin{gathered}
e^{-\alpha-\lambda m_{0}}=\left\{\begin{array}{ll}
\sqrt{4 D^{2}+N^{2}}-2 D & \left(m_{0}=0\right) \\
\frac{N^{2}}{2\left(M_{0}+2 D\right)} & \left(m_{0} \geq 1\right)
\end{array} ;\right. \\
e^{-\gamma}=\frac{n_{0}}{2 M}+1-\sqrt{\left(\frac{n_{0}}{2 M}\right)^{2}+\frac{n_{0}}{M}} \\
e^{-\beta}=\frac{n_{0}}{2 D}+1-\sqrt{\left(\frac{n_{0}}{2 D}\right)^{2}+\frac{n_{0}}{D}} .
\end{gathered}
$$

In Equations (19) and Equations (20), it is seen that given the initial money each agent holds, the number of agents who have zero amount of money is determined by Equation (20.1). Furthermore, $n_{m_{+}}$and $n_{m_{-}}$dependent on $n_{0}$, both have exponential decay functions (Equations (19.2 19.3) and Equation (20.2 20.3)). So the final probability density function of wealth distribution can be expressed as

$$
\begin{gathered}
p_{0}=\frac{n_{0}}{N}=\left\{\begin{array}{cc}
\frac{\sqrt{4 D^{2}+N^{2}}-2 D}{N}\left(m_{0}=0\right) \\
\frac{N}{2\left(M_{0}+2 D\right)} \quad\left(m_{0} \geq 1\right)
\end{array} ;\right. \\
p_{+}=\frac{n_{0}}{N} e^{-\gamma m_{+}}=\frac{n_{0}}{N}\left[\frac{n_{0}}{2 M}+1-\sqrt{\left(\frac{n_{0}}{2 M}\right)^{2}+\frac{n_{0}}{M}}\right]^{m_{+}} ; \\
p_{-}=\frac{n_{0}}{N} e^{-\beta m_{-}}=\frac{n_{0}}{N}\left[\frac{n_{0}}{2 D}+1-\sqrt{\left(\frac{n_{0}}{2 D}\right)^{2}+\frac{n_{0}}{D}}\right]^{m_{-}} .
\end{gathered}
$$

With the limit of bank loan by maximal quantity, the equilibrium statistical distribution of wealth is an asymmetric Laplace distribution, shown as Equations (21.1) (21.3). In other words, the distribution at steady state is determined by initial money, maximum bank loan and the number of trading agents in the system. Furthermore, from the Eqs. 
(21.2) and (21.3), it is easily found that the function $p_{+}$(the right side of the distribution) is a monotonically decreasing function $\left(\partial p_{+} / \partial m_{+}<0\right)$ and exists the maximum $\left(\partial^{2} p_{+} / \partial m_{+}^{2}<0\right)$, while the function $p_{-}$(the left side of the distribution) is a monotonically increasing function $\left(\partial p_{-} / \partial m_{-}>0\right)$ and exists the maximum $\left(\partial^{2} p_{-} / \partial m_{-}^{2}<0\right)$. Hence, we conclude that $p_{0}$ is the maximum of the whole distribution over the amount of money.

Such a result is not surprising: if one interprets this character at steady state, the special characteristics of the group $\left\{n_{0}\right\}$ should be referred to as the essential reason (Chen et. al., 2014). In favor of our argument of the analytical solutions above, we perform the following simulations, where we would like to fit our numerical results with the theoretical function in Eqs. (21.1) - (21.3). Conventionally, we set the initial parameters as $N=25000$, $D=500000$ and $m_{0}=0,10,20$. The data used are drawn from the simulations performed at the time step $t=5000$. The results fitting the analytical function on our measured data are plotted in Fig. 2.
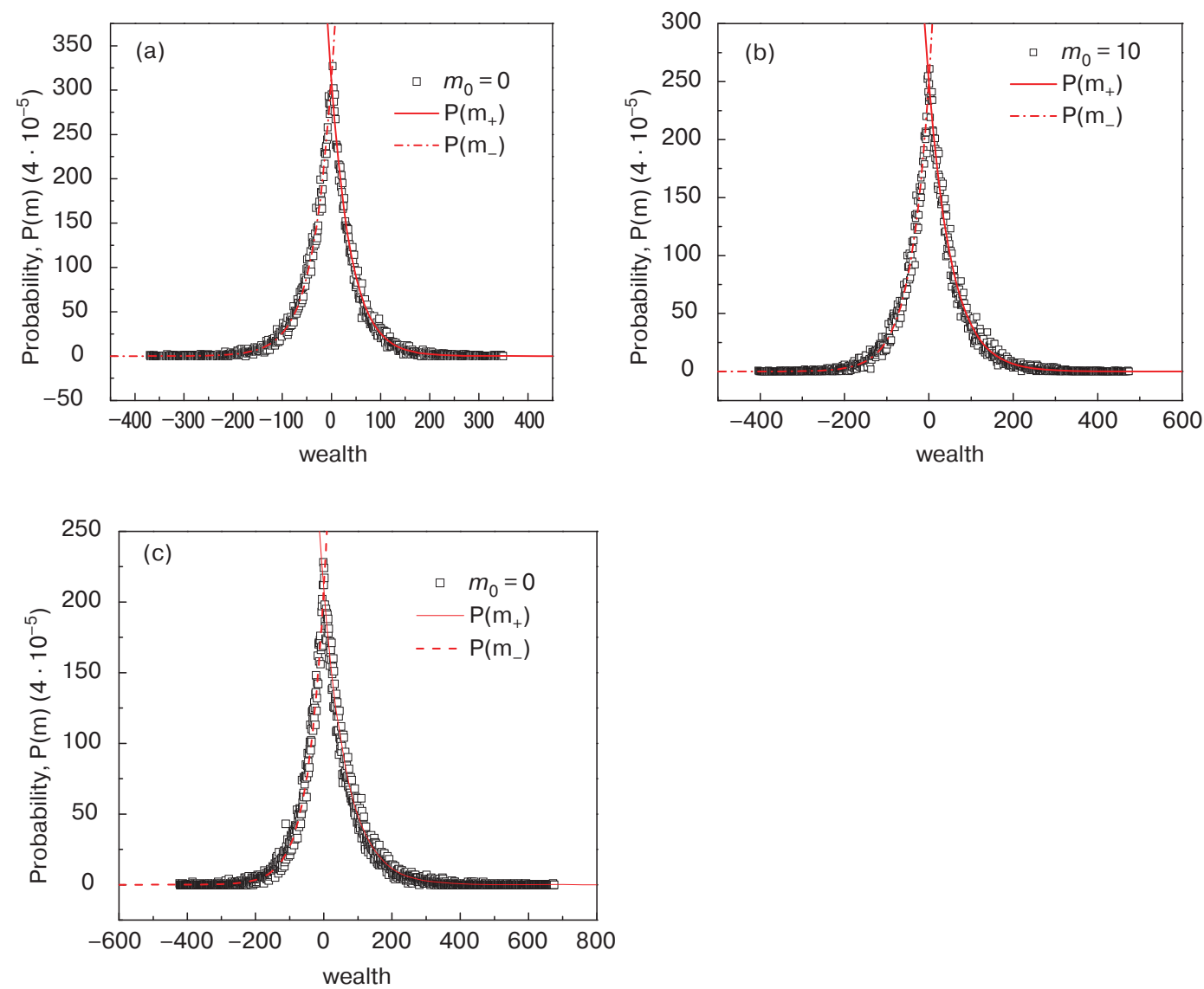

Fig. 2. Plot of the equilibrium statistical distribution of wealth under the boundary condition of maximal bank credit. The scatter points are simulation results, which fit with the functions (solid line) in Eqs. (21.1) - (21.3)

Through the profiles we obtain above, it is seen that the distributions of wealth under the boundary condition of maximal bank loan have only one tip at $m=0$ as found in the analytical solutions before, that is, $p_{0}$ is the maximum value over the probability density function. Next, simulation results plotted in Fig. 2 are well fitted by the analytic solutions, 
which are asymmetric Laplace distributions. To summarize, the outcomes of simulations appear more intuitionistic to confirm our analytical treatment in two respects:

(1) It emerges a sizeable group $\left\{n_{0}\right\}$ as the largest class in our system at the equilibrium.

(2) The trading mechanics follows the Boltzmann statistics, which generates an asymmetric Laplace distribution at the steady state.

\section{Conclusions}

In this paper, we establish a model to explain the power law distribution of wealth which is verified by many empirical studies. The effect of debt constraints on the equilibrium statistical distribution of wealth is investigated by theoretical analysis and numerical simulations. Based on random money transfer models revised by introducing debt and a virtual bank, we consider two types of constraints on debt: one is the individual debt limit; the other is the bank credit limit. Under the former constraint, the random transfer process is described by a master equation on probability density function of money, which has the most probable distribution of wealth as an exponential shape. For the latter case, the Lagrange principle is used to maximize the probability density function of money under a constraint of bank loan, which leads to an asymmetric Laplace distribution of wealth at the steady state. Thus, we confirm that wealth distribution under random money transfer model is consistent with empirical founding in the literature.

However, we notice that debt is not always limited to some extend in the real economy, as the previous financial crises and the present one suggest. Although this study presents a clear description of wealth distribution and explains its formation by theoretical analysis, it is still far from explaining the realistic economic process due to the assumption of controllable debt. So the future studies expect more insights into the economy with nonstationary debt.

\section{REFERENCES}

Abergel F., Chakrabarti B.K., Chakraborti A., Mitra M. (2011) Econo-physics of Order-driven Markets Eds. Springer, Milan. DOI 10.1007/978-88-470-1766-5

Abul-Magd A. Y. (2002). "Wealth distribution in an ancient Egyptian society". Physical Review E 66, 057104. DOI https://doi.org/10.1103/PhysRevE.66.057104

Bak P., N rrelykke S.F., Shubik M. (1999). “Dynamics of money”. Physical Review E. 60. P. 2528-2532.

Basu B., Chakrabarti B.K., Chakravarty S.R., Gangopadhyay K. (2010) Econophysics \& Economics of Games, SocialChoices and Qauntitative Techniques Eds. Springer, Milan. https://doi.org/10.1007/97888-470-1501-2

Benhabib J., Bisin A., Zhu S. (2011). "The distribution of wealth and fiscal policy in economies with finitely lived agents”. Econometrica. 79(1). P. 123-157.

Benhabib J., Bisin A., Lu M. (2017). "Earnings inequality and other determinants of wealth inequality”. American Economic Review. 107(5). P. 593-597.

Braun D. (2001). "Assets and liabilities are the momentum of particles and antiparticles displayed in Feynman-graphs". Physica A. 290. P. 491-500.

Castaneda A., Diaz-Gimenez J., Rios-Rull J.V. (2003). "Accounting for the U.S. earnings and wealth inequality”. Journal of Political Economy. 111(4). P. 818-857. 
Chakrabarti B.K., Chakraborti A., Chatterjee A. (2006) Econophysics and Sociophysics: Trends and Perspectives Eds. Wiley-VCH, Berlin.

Chakraborti A., Chakrabarti B.K. (2000). "Statistical mechanics of money: how saving propensity affects its distribution". The European Physical Journal B. 17. P. 167-170.

Chatterjee A., Chakrabarti B.K., Manna S.S. (2004). "Pareto law in a kinetic model of market with random saving propensity". Physica A. 335. P. 155-163.

Chatterjee A., Yarlagadda S., Chakrabarti B.K. (2005) Econophysics of Wealth Distributions Eds. Springer, Milan, 2005.

Chatterjee A., Chakrabarti B.K. (2007) Econophysics of Markets and Business Networks Eds. Springer, Milan.

Chen S., Wang Y., Li K., Wu J. (2014). "Money Creation Process in Random Redistribution Model”, Physica A. 394. P. 217-225.

Coelho R., N'eda Z., Ramasco J.J., Santos M.A. (2005). "A family-network model for wealth distribution in societies". Physica A. 353. P. 515-528.

Ding N., Xi N., Wang Y. (2003). The European Physical Journal B. 36. P. 149-153.

Drăgulescu A., Yakovenko V.M. (2000). "Statistical mechanics of money". The European Physical Journal B. 17. P. 723-729.

Drăgulescu A., Yakovenko V.M. (2001). “ Exponential and power-law probability distributions of wealth and income in the united kingdom and the united states". Physica A. 299(1). P. 213-221.

Fischer R., Braun D. (2003). "Transfer potentials shape and equilibrate monetary systems". Physica A. 321. P. $605-618$.

Global Wealth Report 2016. Credit Suisse AG Research Institute, 2017.

Hegyi G., Neda Z., Santos M.A. (2007). "Wealth distribution and Pareto's law in the Hungarian medieval society". Physica A. 380. P. 271-277.

Hayes B. (2002). "Follow the money". American Scientisit. 90. P. 400-405.

Ispolatov S., Krapivsky P.L., Redner S. (1998). "Wealth distribution in asset exchange models". The European Physical Journal B. 2. P. 267-276.

Klass O.S., Biham O., Levy M., Malcai O., Solomon S. (2007). "The Forbes 400, the Pareto powerlaw and efficient markets". The European Physical Journal B. 55. P. 143-147.

Levy M., Solomon S. (1996). "Power laws are logarithmic Boltzmannn laws". International Journal of Modern Physics C. 7. P. 595-751.

Levy M., Solomon S. (1997). "New evidence for the Power-law Distribution of wealth". Physica A. 242. P. 90-94.

Levy M. (2003). "Are rich people smarter”. Journal of Economic Theory. 110. P. 42-64.

Levy M., Levy H. (2003). "Investment talent and the Pareto wealth distribution”. Review of Economics and Statistics. 85. P. 709-725.

Pareto V. (1896). La courbe de la r'epartition de la richesse Reprinted in OEeuvres Compl'etes de Vilfredo Pareto, Tome 3: Ecrits sur la Courbe de la R epartition de la Richesse ed G Busoni (Geneva: Librairie Droz, 1965), English translation in Rivista Politica Econ. 87 (1997) 647.

Sinha S. (2006). "Evidence for power-law tail of the wealth distribution in India". Physica A. 359. P. $555-562$.

Yakovenko V. M. (2009) in Encyclopedia of Complexity and System Science eds. Meyers R.A., Springer, Berlin.

(C) Siyan Chen, Yougui Wang, Chengyu Yang, Saul Desiderio, 2018 
Article history:

Received: 31 January 2018

Revised: 20 February 2018

Accepted: 01 March 2018

For citation:

Siyan Chen, Yougui Wang, Chengyu Yang, Saul Desiderio. (2018) Analysis of wealth inequality with a random money transfer model. RUDN Journal of Economics, 26 (1), 140-152. DOI: $10.22363 / 2313-2329-2018-26-1-140-152$

\title{
Bio Note:
}

Siyan Chen, Associate Professor of Business School, Shantou University. Contact information: e-mail: sychen1@stu.edu.cn

Yougui Wang, Professor of School of Systems Science, Beijing Normal University. Contact information: e-mail: ygwang@bnu.edu.cn

Chengyu Yang, Professor of Business School, Beijing Normal University. Contact information: e-mail: cyang@bnu.edu.cn

Saul Desiderio, Associate Professor of Business School, Shantou University. Contact information: e-mail: saul@stu.edu.cn, saul1979@libero.it

\section{АНАЛИЗ ПРИЧИН НЕРАВНОМЕРНОГО РАСПРЕДЕЛЕНИЯ БОГАТСТВ ПОСРЕДСТВОМ МОДЕЛИ ДЕНЕЖНЫХ ПЕРЕВОДОВ}

\author{
Сиян Чен ${ }^{1}$, Йоугуи Ванг $^{2}$, Чэню Янь ${ }^{3}$, Саул Дезидерио ${ }^{1}$ \\ ${ }^{1}$ Школа бизнеса, университет Шаньтоу \\ ул. Даксуе, 243, Шаньтоу, Гуандун, Китай, 515063 \\ 2 Школа системных наук, Пекинский педагогический университет \\ ул. ХинДжиеЛоуВай, 19, р-н Хайдян, Пекин, Китай, 100875 \\ ${ }^{3}$ Школа бизнеса, Пекинский педагогический университет \\ ул. ХинДжиеЛоуВай, 19, р-н Хайдян, Пекин, Китай, 100875
}

Растущий разрыв в распределении богатства является одним из ключевых вопросов, которые обсуждаются во всем мире в последние годы. В этой статье используется модель денежных переводов для объяснения формирования распределения богатства, путем введения двух типов долговых ограничений, а аналитическая функция распределения богатства получается путем принятия статистики Больцмана. С лимитом индивидуального долга показано, что стационарное распределение богатства следует экспоненциальному закону, что подтверждается многими эмпирическими исследованиями. В то время как предел налагается на общую сумму банковского кредита, стационарное распределение становится асимметричным. чения

Ключевые слова: распределение богатства, модель денежных переводов, долговые ограни-

\section{История статьи:}

Дата поступления в редакцию: 31 января 2018

Дата принятия к печати: 01 марта 2018 


\section{Для цитирования:}

Сиян Чен, Йоугуи Ванг, Чэню Янь, Саул Дезидерио. Анализ причин неравномерного распределения богатств посредством модели денежных переводов // Вестник Российского университета дружбы народов. Серия: Экономика. 2018. Т. 26. № 1. C. 140-152. DOI: 10.22363/2313-2329-2018-26-1-140-152

\section{Сведения об авторах:}

Сиян Чен, доцент бизнес-школы Шаньтоуского университета. Контактная информация: e-mail: sychen1@stu.edu.cn

Йоугуи Ванг, профессор школы системных наук Пекинского педагогического университета. Контактная информация: e-mail: ygwang@bnu.edu.cn

Чэню Янь, профессор бизнес-школы Пекинского педагогического университета. Контактная информация: e-mail: cyang@bnu.edu.cn

Саул Дезидерио, доцент бизнес-школы Шаньтоуского университета. Контактная информация: e-mail: saul@stu.edu.cn, saul1979@libero.it 